\title{
O LUGAR DO OUTRO NAS RELAÇÕES AMOROSAS CONTEMPORÂNEAS: UMA LEITURA ÉTICA LEVINASIANA
}

\author{
Maria Juliana Viera Lima \\ Universidade Federal do Ceará \\ José Célio Freire \\ Universidade Federal do Ceará
}

\begin{abstract}
Resumo
A sociedade contemporânea caracteriza-se por uma relação temporal fluida, onde a rapidez e a simultaneidade operam através de formas cada vez mais sofisticadas. 0 outro, na lógica dessa liquidez, é considerado um instrumento de satisfação dos desejos pessoais, pondo em xeque a dimensão ética do seu lugar nesses fenômenos. Este artigo pretende confrontar, a partir do método hermenêutico de Gadamer, as discussões sobre os relacionamentos contemporâneos em Bauman, Giddens e Jean Paul Sartre, subsidiando a discussão através de uma leitura ética desses fenômenos pela perspectiva da alteridade radicalizada de Lévinas. Nesse sentido, buscamos o lugar do outro na relação amorosa e discutimos as possibilidades de uma escuta desse outro marcada não pelas demandas narcísicas de um modelo hedonista de sociedade, mas pela exigência ética inexcedível - ser pelo e para o outro. Nessa perspectiva ética, não encontramos o lugar do outro nas relações amorosas contemporâneas.

Palavras-chave: Ética; Amor; Relações Contemporâneas.
\end{abstract}

\section{THE OTHER'S PLACE IN THE CONTEMPORARY RELATIONS: A LEVINASIAN ETHIC READING}

\begin{abstract}
Contemporary society is characterized by a temporal fluid relationship where speed and concurrency operate increasingly through sophisticated ways. The other, in this logic, is considered an instrument of satisfaction of personal desires, putting into the question the ethical dimension of their place in those phenomena. This article aims to confront, through hermeneutic method of Gadamer, the propositions about the love relationships with Bauman, Giddens and Jean Paul Sartre; at the same time, this article will make an ethical reading of the phenomenon through radicalized otherness proposed by the philosopher Lévinas. Therefore, we sought the place of the other in loving relationships and we discussed the possibilities of a listening of this other, not by narcissistic demands of a hedonistic model of society, but by surpassing ethical requirement - to be by and for the other. In this ethical perspective, we did not find the place of another in contemporary love relationships.
\end{abstract}

Keywords: Ethics; Love; Contemporary Relationships. 


\title{
EL LUGAR DEL OTRO EN LAS RELACIONES AMOROSAS CONTEMPORÁNEAS: UNA LECTURA ÉTICA LEVINASIANA
}

\begin{abstract}
Resumen
La sociedad contemporánea se caracteriza por una relación temporal fluida, donde la rapidez y simultaneidad operan a través de formas cada vez más sofisticadas. El otro se considera un instrumento de satisfacción de los deseos personales, poniendo en tela de juicio la dimensión ética del lugar de otros en estos fenómenos. Este artículo pretende, enfrentar, desde el método hermenéutico de Gadamer, las proposiciones teóricas sobre la relación amorosa con Bauman, Giddens y Jean Paul Sartre, y va hacer una lectura ética través de la alteridad radicalizada propuesta por Lévinas. En este sentido, buscamos el lugar del otro en la relación amorosa y discutimos las posibilidades de una escucha de ese otro, no por las demandas narcisistas de un modelo hedonista de sociedad, sino por una exigencia ética -ser por el y para el otro. En ésta perspectiva ética, no hemos encontrado el lugar del otro en las relaciones amorosas contemporáneas.
\end{abstract}

Palabras clave: Ética; Amor; Relaciones Contemporáneas.

\section{INTRODUÇÃO}

O estudo da sociedade contemporânea e das repercussões de suas características fundamentais sobre os sujeitos implica em levar em consideração também as relações humanas mais próximas que envolvem afetividade e sexualidade. No campo das relações amorosas sobressaem os mais variados elementos, tais como o ciúme, a duração dos relacionamentos, o envolvimento dos parceiros, a fidelidade, os jogos sexuais, o compromisso etc.

A sociedade atual, teorizada por Bauman (2004) como uma sociedade líquida, caracteriza-se por relações temporais fluidas, nas quais a rapidez e a simultaneidade dos laços operam das mais diversas formas. O outro, na lógica dessa liquidez, é considerado um instrumento de satisfação dos desejos pessoais, passível de ser descartado no momento em que não trouxer mais nenhum benefício.

Tais modelos relacionais são postos em xeque na medida em que suscitam questionamentos éticos em torno do lugar que o outro ocupa nesses fenômenos. Deste modo, tomamos as proposições de Emmanuel Lévinas, filósofo lituanofrancês, acerca do componente ético existente nas relações. $O$ pensamento de Lévinas constitui-se na ética da alteridade radical que coloca o outro numa posição de primogenitura: o outro é soberano, me chama, me exige na forma de um mandamento ético e sou responsável por ele. Seu pensamento nos abre a possibilidade de repensar o lugar do outro, o cuidado com ele e a responsabilidade por ele, a partir da alteridade radicalizada.

Neste artigo pretendemos, portanto, a partir das discussões em torno dos relacionamentos afetivos na contemporaneidade, confrontar as proposições teóricas de Zygmunt Bauman (2004, 2008a, 2008b) e Anthony Giddens (1993), na sociologia, e Jean Paul Sartre (1997), na filosofia existencialista, subsidiando a discussão de acordo com uma leitura ética desses fenômenos a partir da alteridade radicalizada de Emmanuel Lévinas (1980, 1982), horizonte ético de 
onde lançaremos o olhar sobre as outras teorias. Nesse sentido, buscaremos o lugar do outro na relação amorosa e discutiremos as possibilidades de uma escuta deste marcada, não pelas demandas narcísicas de um modelo hedonista de sociedade, mas por uma exigência ética inexcedível - ser pelo e para o outro aquém de toda liberdade presumida e valorizada no modelo societário atual.

\section{MÉTODO}

Por se tratar de uma pesquisa de caráter teórico, seguiu-se uma orientação metodológica qualitativa, direcionada pela proposta hermenêutica de Gadamer (2008), na qual o intérprete chega aos textos já com pressupostos (preconceitos), mas estes precisam ser suspendidos no momento inicial para, posteriormente, serem confrontados com os elementos resultantes da análise. Dessa maneira, o pesquisador identifica os horizontes conceituais concernentes ao tema, promove uma fusão destes horizontes de análise e chega a uma nova concepção sobre o mesmo. Nas palavras de Gadamer (2008),

Uma consciência formada hermeneuticamente tem que se mostrar receptiva, desde o princípio, para a alteridade do texto. Mas essa receptividade não pressupõe nem "neutralidade" com relação à coisa nem tampouco autoanulamento, mas inclui a apropriação das próprias opiniões prévias e preconceitos, apropriação que se destaca destes (p. 405).

Nesse sentido, procedemos a uma leitura analítica dos textos escolhidos, em Bauman, Giddens e Sartre, tomados como horizontes de discussão sobre o tema do amor na contemporaneidade, para, em seguida, confrontarmos suas ideias centrais com o pensamento levinasiano. Ao mesmo tempo, mantivemos em suspensão nossos próprios preconceitos, no sentido gadameriano do termo, a fim de a eles voltarmos quando da discussão final. Tentamos, assim, provocar uma fusão de tais horizontes teóricos e chegar a uma nova compreensão da questão inicial, a saber, o lugar do outro nas relações amorosas contemporâneas. Escolhemos tais autores por entendermos que fazem parte de uma tradição crítica da sociedade e por terem eles tratado da questão das relações amorosas ou íntimas na contemporaneidade.

\section{RESULTADOS E DISCUSSÃO}

Coelho Junior e Figueiredo (2004) analisam a constituição do sujeito, em acordo com matrizes organizadoras e elucidativas de diferentes dimensões da alteridade. Pensaremos, a partir deste modelo, a construção das relações amorosas. Ele aponta para quatro matrizes que constituem-se em modos de produção da intersubjetividade, sendo elas: a trans-subjetiva, a interpessoal, a intrapsíquica e a traumática. 
A matriz da intersubjetividade trans-subjetiva é marcada pelos pensamentos dos autores fenomenológico-existenciais, e refere-se à proposição de que a alteridade é constituinte das experiências subjetivas por seu caráter de inclusão primordial. A alteridade, para eles, é inaugural e constitui-se como um solo trans-subjetivo que é anterior até mesmo à ideia de haver um Eu que se opõe ou se relaciona com o Outro. Há uma indiferenciação e uma impossibilidade de separação entre o Eu e o Outro (Coelho Júnior \& Figueiredo, 2004).

A matriz da intersubjetividade interpessoal, diferentemente, pensa a subjetividade a partir da interação entre o organismo e os sujeitos individuais, tendo como pensamento marcante o interacionismo simbólico de George Mead. "Ninguém pode se dotar de um mim e de uma consciência senão pela mediação do outro e de suas respostas" (Coelho Júnior \& Figueiredo, 2004, p. 22), são os outros que atribuem sentido aos meus gestos, e a eles meus gestos são dirigidos. Os outros completam e significam minhas ações a partir da interação.

Já a perspectiva da intersubjetividade intrapsíquica, pensa a dimensão intersubjetiva como fundante no plano psíquico. A experiência intersubjetiva não precisa se dar na realidade externa para que produza consequências em níveis psíquicos, dado que o outro está presente pelos processos de identificação, incorporação e introjeção com os objetos internos. Nessa matriz, defendida pelos teóricos da psicanálise, o outro comparece como uma presença-ausência, existindo simbolicamente no psiquismo (Coelho Júnior \& Figueiredo, 2004).

Os autores apontam, por fim, que Lévinas se insere num modelo de pensamento classificado por eles como matriz da intersubjetividade traumática. Para estes, o pensamento levinasiano propõe uma subjetividade que é constituída a partir do trauma que o outro me provoca: "O outro concreto e singular me precede e me traumatiza e com isso me constitui" (Coelho Júnior \& Figueiredo, 2004, p. 20). A experiência subjetiva é abertura permanente e inevitável ao outro, onde o outro me chega exigindo uma resposta e devo estar a seu serviço.

Lévinas (1982) destaca, a partir da ética da alteridade radical, a supremacia do outro diante de mim. O filósofo nos abre para a possibilidade de nos fragilizarmos diante do outro e traz a responsabilidade por este como algo que estrutura e funda a nossa subjetividade, destacando que ela existe até mesmo quando não a assumimos e é apenas uma incumbência. "O rosto pedeme e ordena-me" (Lévinas, 1982, p. 89), ou seja, o outro me intima e não há como fugir dele.

A subjetividade não é algo para si, ela é inicialmente para o outro. Este se aproxima de mim enquanto sou responsável por ele, fundando-me a partir daí. "A subjetividade, ao constituir-se no próprio movimento em que lhe incube ser responsável pelo outro, vai até à substituição por outrem" (Lévinas, 1982, p. 92). Não há fuga para tal imposição, a minha primeira resposta ao outro é eisme aqui. Só a partir dessa resposta é que me torno eu, na realidade me torno 
mim, pois o mim é o eu atingido pelo outro, respondendo ao outro. Quanto mais passivo sou, mais aberto ao Infinito me torno. Para Haddock-Lobo (2006), em sua análise da ética levinasiana, o outro permite a possibilidade do eu reencontrar-se, pois ele é o sentido primordial que possibilita o reencontro de nossa humanidade.

Pensar no amor a partir da alteridade radicalizada, em Lévinas, é pensar numa relação com o outro que é fundante e estruturante para a subjetividade. $O$ outro é pensado como supremo, como aquele a quem devo tudo e por quem tenho total responsabilidade, esta que me constitui e me faz um eu. Como o próprio autor nos indica:

A não-indiferença onde eu sou para o outro, enquanto o outro é Outrem e próximo, está para além de todo engajamento no sentido voluntário do termo pois, precisamente, liberando nesta extrema passividade um sujeito indeclinável e único, a responsabilidade, significação da não-indiferença, é em sentido único, de Mim [Moi] ao outro (Lévinas, 1978, p. 61, trad. dos autores).

As experiências de subjetivação em Lévinas não são uma simples assimilação do outro e do que ele me traz, são convivências e transformações diante daquilo que difere de mim e me faz outro. Assim, a subjetivação é advinda do contato com a diferença, com aquilo que não é igual e que não tem relação com o império do mesmo. Essa relação com a diferença e, portanto, com a alteridade é uma experiência traumática, pois "o contato com o outro passa pelo inevitável impacto da não adaptação plena, da impossibilidade de adequação" (Haddock-Lobo, 2006, p. 21). O outro sempre me excede e não é possível haver um perfeito encaixe nessa relação com a alteridade. O contato com o outro me causa fraturas e exige um trabalho permanente e irrealizável de adaptação entre mim e o outro.

Lévinas diz-nos que somos afetados pelo outro e que esse tem primazia sobre nós. O outro é primogênito, ele chegou primeiro e minha função é apenas responder a ele. O outro me intima a uma resposta, sendo essa resposta uma relação ética por excelência que me funda e me estrutura. Mais uma vez Lévinas nos convoca a pensar esse outro de forma radical:

A significação - o um-por-outro - a relação com a alteridade - tem sido analisada na presente obra como proximidade, a proximidade como responsabilidade por outrem, e a responsabilidade por outrem - como substituição: em sua subjetividade, em seu refúgio mesmo de substância separada, o sujeito se manifesta expiação-por-outrem, condição ou incondição de refém. (Lévinas, 1978, p. 282, trad. dos autores)

Segundo Lima (2007), Lévinas elege o conceito de Eros, em detrimento de todas as outras concepções de amor na Grécia Antiga, como o sentimento que possibilita a abertura ética com o outro, já que Eros é a relação com a alteridade. O amor, para Lévinas, é o amor que se doa e que se coloca à disposição do outro, indo ao seu encontro. A dimensão da alteridade se coloca na relação com 
a diferença, é a diferença que nos chama a estar em relação. Diz-nos Lévinas que "O amor visa Outrem, visa-o na sua fraqueza (...) Amar é temer por outrem, levar ajuda à sua fraqueza" (Lévinas, 1988, p. 235).

O amor vivido nas relações contemporâneas, a partir da busca pela alma gêmea, é amar o outro pelo que ele tem de semelhante, amo aquele que se assemelha a mim, mas é pela diferença que a alteridade se constitui. Tornar o outro semelhante é anular sua alteridade, é destruí-lo e torná-lo o mesmo. "Desta maneira, o outro garante minha alteridade, minha diferença e não tem nada a ver com fusão, está mesmo no extremo oposto à ideia de amor" (Marcondes Filho, 2007, p. 61).

A partir da alegoria dos seres andrógenos, apresentada por Aristófanes em O Banquete (Platão, 1972), conseguimos compreender essa busca pela alma gêmea tão presente no cotidiano. Segundo o mito, os seres andrógenos teriam ambos os gêneros e seriam, por isso, seres muito poderosos; até que eles tentaram subir ao Olimpo na tentativa de matar os deuses. Na batalha, os andrógenos foram domados e, como castigo, Zeus os separou em duas metades, os condenando a serem incompletos e a buscarem constantemente sua outra parte na tentativa de retomarem a unidade.

Essa leitura acerca do amor irá, segundo Braz (2005), perpassar as concepções seguintes e chegará até ao pensamento atual, o influenciando. A partir dela, acredita-se que a missão da vida é encontrar a outra parte que falta para que haja novamente a inteireza.

Seríamos seres eternamente incompletos que encontrariam a completude em outrem, dependendo desse encontro para alcançar a felicidade. Utilizandonos dos escritos de Emmanuel Lévinas, podemos inferir que a busca pela alma gêmea na tentativa de incorporá-la a nós para sermos completos, remete-nos ao império do Mesmo, à tentativa de anular toda e qualquer diferença, toda e qualquer alteridade.

Bauman (2008b) se faz presente nessa discussão e destaca que ao desejar o outro para que ele me complete, tento anular o que o outro traz em sua diferença. Contrapõe, desta forma, duas formas de intersubjetividade (p. 207):

o que você deseja, você quer usar, consumir, despir de alteridade, tornar sua possessão ou ingerir - fazê-lo parte de seu corpo, uma extensão de você mesmo. Usar é aniquilar o outro para o bem da própria pessoa. Amar, ao contrário, significa valorizar o outro por sua alteridade, fazê-lo florescer e prosperar. (...) Usar é tirar, valorizar é dar.

Em Lévinas, o amor mora no irrevelado, o rosto que se manifesta a partir dele mesmo, sem conceito, sem revelação, traz-me a dimensão do infinito. "O rosto é a própria identidade de um ser. Ele se manifesta a partir dele mesmo, sem conceito. (...) O rosto está presente na sua recusa de ser conteúdo. Neste sentido, não poderá ser compreendido, isto é, englobado" (Lévinas, 1980, p. 173). 
Tendemos a querer possuir o outro, e usamos o amor como instrumento para aprisioná-lo, consumimos o outro do mesmo modo como adquirimos os produtos que são expostos nas prateleiras dos supermercados. Este seria o equívoco cometido em nome do amor. Uma relação centrada na utilidade e satisfação de desejos próprios é o extremo oposto do amor, da amizade e da solidariedade (Bauman, 2008a). O amor, para Lévinas (1988), nada tem de posse, ele é relação com algo que sempre foge, não podemos dominar o outro e nem possuí-lo, pois o outro jamais se torna nosso, ele se retira em seu mistério. "Ele está fora de meus poderes, é intraduzível, jamais poderá ser englobado, apossado, compreendido" (Marcondes Filho, 2007, p. 62).

O outro não pode ser visto como uma totalidade, pois ele estaria sendo dominado e por isso destruído; o outro deve ser visto em relação ao Infinito que ultrapassa essa totalidade. Ele se manifesta pelo Rosto, e o Rosto está expresso em todo ser humano. Por isso, "O amor para Lévinas é mais que um sentimento subjetivo por outrem; ele é antes de tudo um apelo, uma força que move o agir ético" (Lima, 2007, p. 98). O outro será sempre diferente, ele não poderá ser fundido comigo ou transformado em semelhante, pois assim a alteridade ficaria passível de ser anulada. "O outro estará sempre ao nosso lado, por mais que não queiramos, estampando em seu rosto sua radical diferença" (Haddock-Lobo, 2006, p. 48).

O Rosto se expõe íntegro, sem defesas, despido, nu. O Rosto tem uma pobreza existencial, é frágil, está exposto, parece ameaçado e isso nos convida ao um ato de violência que o próprio Rosto nos proíbe de cometer. O outro é "o pobre por quem posso tudo e a quem tudo devo" (Lévinas, 1982, p. 80). Posso matá-lo porque ele é frágil e indefeso, mas não o posso fazer, pois o outro aparece com o mandamento ético não matarás, e isso é uma ordem que significa que a alteridade do outro não pode ser destruída. O Rosto aparece com sentido só para ele, não é visto e não pode ser transformado em conteúdo. O Rosto não pode ser visto, pode ser apenas escutado. A visão é da ordem do poder sobre o outro, ela procura uma adequação que absorve o ser, já a escuta é um ato de vulnerabilidade e abertura que não visa ao enquadramento.

Lévinas assinala que a totalidade é uma tentativa de limitar e conhecer tudo, é uma tentativa de anular a diferença e instalar o império do mesmo, do que é igual e conhecido. Já a ideia de infinito nos aponta para aquilo que não pode se delimitado e totalizado, para a relação com a diferença, com o desconhecido.

Carneiro (1998) defende que quando os amantes desejam o outro por inteiro, os indivíduos funcionam como reservatórios de expectativas latentes que podem dar a sensação de esvaziamento. As expectativas são grandes e há uma extrema idealização do outro e demasiada exigência em relação a si mesmo, gerando grandes tensões entre os amantes. 
Sartre (1997), ainda no cenário de dominação e assimilação do outro, fala do papel deste no congelamento da existência humana; é ele (mais precisamente o seu olhar) que tem o poder de congelar o para-si e o tornar um em-si. A constituição do sujeito, em Sartre, não se dá para um eu solitário, o eu precisa estar em contato com o outro, estabelecendo relação (Zanello, 2007).

O conceito sartreano de em-si diz respeito ao que se é, àquilo que está pronto e acabado, não podendo ser nada para além disso e nem o contrário disso. O em-si mostra-se avesso à alteridade, pois não estabelece relações com o outro e se esgota em si mesmo. Deste modo, no em-si não há alteridade, pois não há relação com o outro; não me constituo com o outro, já não me lanço no mundo e não me faço a partir do olhar do outro (Silva, 2010).

O para-si, contudo, segundo Silva (2010), é um ser que não pode ser considerado uma coisa, ele traz o nada em seu cerne. O humano nasce do nada, com essa fenda, esse hiato que tenta ser preenchido lançando-se na existência através da liberdade, considerada ontológica pela perspectiva sartreana. Estar no nada representa um movimento de constituição do humano, já que "ao estar separado de si surge a necessidade de um movimento de busca de completude, de preencher aquilo que falta, ou seja, de realizar aquilo que não é plenamente realizado" (Santos, 2011, p. 50). O para-si, portanto, existe fora de si, lançado, estando incompleto, ele não pode adquirir estabilidade, pois nunca é, está sempre sendo, em construção (Silva, 2010).

No caso do congelamento da existência através do olhar do outro, o ser em-si diz respeito ao ser que é coisificado e se torna objeto a partir da visão do outro. O sujeito na condição de em-si é aquele cuja existência é determinada e que não está mais fundada no devir da existência humana, que é sempre uma construção. O olhar do outro me vem como uma constante ameaça. A partir do olhar coisificador do outro, minha transcendência fica ameaçada, corro o risco do congelamento da existência, de ser-em-si.

Consumimos e descartamos o outro rapidamente, sempre em busca de algo que satisfaça mais e melhor os nossos desejos. Dessa necessidade de apossar-se do outro, de tê-lo sob o controle advém o ciúme e a insegurança por perceber esse outro em desacordo com nossas expectativas. Estamos, segundo Bauman (2004), sempre querendo descartar o outro, anulá-lo, deletá-lo. Ele aponta as características da modernidade líquida, focando principalmente nas consequências desta para as relações humanas. Para o sociólogo, as relações humanas estão cada vez mais flexíveis e cada vez menos os sujeitos se arriscam em alguma relação duradoura que não seja pautada apenas no hedonismo característico das sociedades contemporâneas.

Os amantes da modernidade líquida dificilmente se apegam a algum compromisso mais sério, pois não se consegue abrir mão da suposta miríade de possibilidades que o mercado oferece; destacando aqui o excesso no qual estamos imersos. Excesso esse que nos coloca de frente para o nada, para a 
impossibilidade de completude, apesar de haver tantas opções. Bauman (2004, p. 7) comenta que, no cenário moderno:

(...) se espera e se deseja que as "possibilidades românticas" (e não apenas românticas) surjam e desapareçam numa velocidade crescente e em volume cada vez maior, aniquilando-se mutuamente e tentando impor aos gritos a promessa de "ser a mais satisfatória e a mais completa".

Os amantes da modernidade tardia não se relacionam, mas se conectam uns aos outros: "em vez de relatar suas experiências e expectativas utilizando termos como 'relacionar-se' e 'relacionamentos' as pessoas falem cada vez mais [...] em conexões, ou 'conectar-se' e 'ser conectado'. Em vez de parcerias, preferem falar em "redes"' (Bauman, 2004, p. 8) e se conectam através destas redes, que são facilmente deletáveis e descartáveis. Nas conexões em rede, o engajamento mútuo não é necessário, nelas conectar-se é tão mais fácil e legítimo como desconectar-se.

Nesse contexto, os modelos de construção e de dissolução dos relacionamentos estão firmados em um estado de prazer contínuo, haja vista que "o amor e o sexo não escaparam ao princípio consumista do mais querer que produz o rápido esgotamento do que se tem. Evitamos as dores de amores pelo outro e afundamos nas dores do vazio de si mesmo" (Rios, 2008, p. 424). Os amantes são capturados pelos padrões capitalistas de aquisição e descarte e os reproduzem nos relacionamentos íntimos, nos quais a dinâmica do investimento/desinvestimento no outro é fundamentada na política da benesse e das vantagens.

Outra característica muito marcante dos amores atuais é a necessidade de exposição dos relacionamentos através das mais diversas redes sociais. Estes parecem existir até o momento em que dura a exploração da imagem. Numa reflexão ética sobre isso, buscamos Lévinas (1988) quando este nos fala da questão do feminino, que seria a dimensão mais pura das relações de alteridade através da fragilidade e sensibilidade com e pelo outro e é a condição de recolhimento em uma morada, pois sua hospitalidade é anônima, secreta e misteriosa. Algo que diverge da espetacularização do amor, que deve ser aplaudido, adorado e que não existe sem exposição ou sem a visibilidade tornada necessária para que haja reciprocidade no relacionamento.

Em Lévinas, as relações amorosas são uma negação da sociedade, o eu é satisfeito apenas pelo tu, é apenas esse outrem que justifica o meu ser. "O amor e seu calor afetivo bastam para essa realização, este contentamento, esta plenitude, sendo a sociedade do amor uma sociedade a dois, sociedade de solidões refratária à universalidade" (Marcondes Filho, 2007, p. 61). Uma relação que não necessita de exposição.

Os relacionamentos amorosos conflitam em dois polos que, quando não antagônicos, retratam um mesmo movimento de ir e vir das relações: o desejo 
de um confinamento relacional ou o desejo de uma liberdade relacional. Bauman (2004) aponta essa ambiguidade como consequência da fragilidade dos laços humanos, na qual os indivíduos são estimulados a estreitar os laços que os unem, até para mantê-los vivos, ao mesmo tempo em que tentam manter esses laços frouxos para que os compromissos com outrem não os sufoquem.

Segundo Carneiro (1998, p.5), "os ideais contemporâneos de relação conjugal enfatizam mais a autonomia e satisfação de cada cônjuge do que os laços de dependência entre eles". O casal contemporâneo é demandado saber lidar constantemente com o difícil equilíbrio entre a relação amorosa com o outro e a individualidade. A fragilidade dos laços e a efemeridade das relações disparam o desejo de intensificá-los, ao mesmo tempo em que o mais certo é deixá-los desprendidos para não impedir a formação de outros. O atar e desatar com tanta facilidade dos laços humanos neutraliza a responsabilidade que o amor nos impõe. Amar com responsabilidade para com outrem não é uma passagem fácil, pois o amor exige ação, escolha e implicação (Bauman, 2008a).

Nesse sentido, se, por um lado, os amantes devem sustentar o crescimento e o desenvolvimento de cada um, por outro devem criar um espaço para a relação, no qual vivenciam a realidade comum do casal, seus desejos e projetos conjugais. Carneiro (1998) destaca a importância de haver, na relação, uma reorganização dos papeis dos amantes; afinal, são histórias, maneiras de agir e pensar, desejos e sujeitos diferentes que se encontram e passam a construir uma relação juntos. Essa dinâmica é repleta, dentre outras coisas, de conflitos e entraves, sendo crucial que se construa uma zona comum de interação entre os amantes para formar uma espécie de identidade conjugal. Já não se fala mais de quem é este ou aquele, mas quem são eles em relação, dentro da relação.

Apesar desses conflitos entre a individualidade e a relação do casal, Giddens (1993) aponta a liberdade relacional como a característica primordial do relacionamento puro. Os relacionamentos puros seriam relações de sentimentos recíprocos nas quais o casal se manteria unido enquanto tal fato fosse aceito por ambos; aqui as relações por si só seriam reforçadoras, não necessitando se apegar a nenhuma convenção social. Para tanto, o casal deveria estar em constante diálogo a fim de acordar o melhor para os dois, até segunda ordem.

O relacionamento puro, pois, só permanece enquanto ambas as partes estão satisfeitas com a relação, não havendo nada que as prenda. Pretto, Maheirie e Toneli (2009) enfatizam que no relacionamento puro "o casal investe na relação pela própria relação, a qual só continua enquanto ambas as partes considerarem que obtêm dela satisfações individuais suficientes" (p. 397).

Bauman (2004, p. 52), em uma crítica à possibilidade das relações puras, afirma que a opção para finalizar um relacionamento no momento em que ele não trouxer mais nenhum benefício dá abertura para que os amantes não cultivem e não cuidem de suas relações, já que elas são apenas um acordo 
prévio de vantagens. Destaca que os "compromissos 'até que a morte nos separe' se transformam em contratos 'até que a satisfação diminua', temporais por definição e planejamento - e receptivos a serem rompidos unilateralmente sempre que um dos parceiros fareje vantagens em optar por sair do relacionamento" (Bauman, 2008a, p. 198-199).

Deste modo, os laços e relacionamentos com o outro são equiparados a produtos de consumo e, por isso, são analisados segundo os mesmos critérios. Quando servem e estão de acordo com os critérios dos amantes, são bons para uso; porém ao menor sinal de inutilidade, são descartados ou trocados por novos modelos que tragam cada vez mais satisfação, até que o ciclo volte a se repetir.

Longe da visão romântica e idealizada do amor, na qual este é entendido como um dom maior que eleva os sujeitos e os faz viver em paz e calmaria, Sartre (1997) o situa como a primeira experiência com o outro, como um empreendimento de projetos existenciais que rumam para possibilidades. É também, além de um empreendimento, um conflito, pois nos coloca em contato com a liberdade do outro. Sartre (1997) define as formas de amor contemporâneas como relações sadomasoquistas, dado que sempre há alguém que irá se submeter ao outro e alguém que irá submeter o outro às suas vontades.

Nessas experiências sadomasoquistas, os amantes tentam neutralizar a transcendência do amado, tornando-os em-si. O amor, nesse sentido, busca a síntese impossível entre o eu e o outro. Penha (1982, p. 64-65) esclarece-nos:

O amante ambiciona possuir a pessoa amada como sujeito, não como objeto, coisa, julgando assim dominar a essência do outro ao mesmo tempo em que recupera sua subjetividade, o eu que o outro the roubara. Igualmente deseja ser amado como sujeito. Exige que ambos, possuidor e possuído, sejam sujeitos. Mas isso é impossível. Malogrado em seu inferno, o amante sofre. Percebe que não é compreendido pela criatura amada e não consegue fazer com que ela se sinta compreendida por ele. (...) Aparentemente, a alternativa para o conflito é uma relação cujos termos se complementam: o sadismo e o masoquismo. O masoquista (...) abdica de sua liberdade e subjetividade, obstáculos, supõe, à sua assimilação pelo outro, que as conserva consigo. Pretende, dessa forma, ser desfrutado como objeto e se sentir como tal. O empenho se revela inútil, pois lhe é impossível renunciar a se ver como sujeito, frustrando, assim, o esforço do sadista em fazê-lo sentir-se a si mesmo como objeto.

A assimilação do outro através da experiência do amor sadomasoquista é a tentativa frustrada de escaparmos da conflitualidade do amor, estando a liberdade do ser fadada ao malogro, pois "o 'encanto' que envolve as consciências do par amante-amado pode ser quebrado a qualquer momento. Em outras palavras, o amado pode subitamente ser tomado pelo amante como um mero 'objeto' entre outros no meio do mundo" (Silva, 2010, p. 60). O amor é conflito, portanto, tal como todas as outras formas de relacionamento humano. 
O amor ideal para Sartre, se é que possa existir tal ideal de amor, seria, então, o amor no qual os envolvidos irão auxiliar o outro em seu projeto existencial, sem haver submissão e nem opressão. Ao invés de ser buscada uma assimilação dos eus, é almejado um compartilhamento dos mesmos, o qual se configura como um meio termo entre o individualismo exacerbado e a submissão de um amante ao outro.

Nos projetos existenciais dos amantes, segundo Pretto et al. (2009, p. 400):

... o futuro torna-se definidor para a parceria; ou seja, é sobre metas, planos, objetivos e estratégias que os amantes estruturam e atribuem sentido à sua "união". É transcendendo o plano dos prazeres e alegrias imediatas, em função de uma felicidade que se projeta duradoura, de compromissos e escolhas com a própria existência de cada um e do casal, bem como a partir de pequenas realizações nesse percurso, que os parceiros buscam realizar-se como amantes.

Os autores também afirmam que o amor, na perspectiva sartreana, se define como uma parceria entre dois sujeitos livres que escolhem compartilhar experiências e vivências e se permitem modificar seu projeto existencial para que o projeto existencial do outro também seja levado em consideração. Seria uma relação que não subjuga o outro, mas o afirma como uma liberdade, "o amor exige, assim, o reconhecimento do outro enquanto liberdade e de si próprio como liberdade" (Pretto et al.,2009, p. 400).

$\mathrm{Na}$ perspectiva levinasiana, há uma total submissão ao outro, o outro é superior a mim e me intima ao mandamento ético. Ou, como sintetiza Poirié (2007, p. 43): "Lévinas (...) nos propõe um amor realmente para-com-o-outro em que nenhum poder (nenhum saber) se exerce, em que o outro é amado em (e não por, romanticamente) sua alteridade, sua invisibilidade, sua 'estrangeireidade'"'.

Em Sartre, o amor também caminha para essa abertura com o outro, mas não como mandamento, e sim, como escolha. Os amantes irão auxiliar o outro em seu projeto existencial, sem haver submissão e nem opressão, utilizando-se de suas liberdades individuais no auxílio do projeto existencial de outrem.

Podemos resgatar algo semelhante em Giddens (1993), quando este traz o amor confluente como fruto de um relacionamento puro. O amor confluente seria, então, uma abertura ao outro na medida em que é eminentemente baseado na confiança e na negociação, no qual todas as decisões são tomadas a partir de acordos reflexivos e democráticos e nenhum dos envolvidos submete o outro às suas vontades. Em ambos os casos, o outro não é aprisionado e a relação é pautada pela lógica da alteridade radicalizada.

Em Giddens (1993) também destacamos a noção de intimidade; nela, os casais permitem exporem-se e revelarem "emoções e ações improváveis de serem expostas pelo indivíduo para um olhar público mais amplo" (p. 153). De 
certa forma, esse espaço íntimo é uma morada serena e confiada, é uma fuga do mundo e uma busca por algo mais pessoal. A morada, para Lévinas (1988), é o local da constituição do ser; a casa é a proteção do mundo que nos ameaça; na casa eu me separo do mundo e posso me constituir como sujeito. $\mathrm{O}$ amor, para tanto, é o lugar de morada, na qual o sujeito abriga-se e constitui-se nesse encontro com o outro que o forma e o intima a mandamentos éticos.

\section{CONSIDERAÇÕES FINAIS}

A partir das diferentes e, por vezes, divergentes perspectivas de se pensar o amor podem-se encontrar pontos importantes nas teorias aqui trabalhadas que auxiliam a análise, sempre inconclusa, de como se dão as relações amorosas na contemporaneidade.

No desenvolvimento das discussões tecidas ao longo desse artigo, apresentamos diversas concepções acerca do amor de acordo com Zygmunt Bauman (2004, 2008a, 2008b) e Anthony Giddens (1993), na sociologia, e Jean Paul Sartre (1997), na filosofia existencialista; não havendo como determinar juízos morais sobre estas ou valorar modos corretos ou incorretos de relacionamento. Foi possível, porém, questionar a dimensão ética contida nessas relações nos baseando na perspectiva da alteridade radical de Lévinas (1980, 1982), quando este nos abre para a possibilidade de se fragilizar diante do outro e se fazer responsável por ele.

Não há, em Lévinas $(1980,1982)$, opção de se escolher o outro ou de firmar um acordo com base nos desejos e necessidades atuais dos amantes. $O$ amor não vem como escolha, modelo de relacionamento explorado em Sartre (1997) e Giddens (1997), mas a partir de um mandamento ético que me funda e me torna sujeito através da submissão ao outro. Não aparece também como um objeto de satisfação imediata, pois não há a possibilidade de consumir e, por conseguinte, descartar o outro, já que sou responsável por ele. Essa relação com o outro não é fundada pela lógica do pertencimento ou da apropriação. Já não se fala aqui de relacionamentos amorosos nos quais os amantes estão constantemente tentando anular as diferenças do amado, tornando-o similar. O outro não pode ser igual, ele não poderá ser fundido comigo, pois se assim fosse, a alteridade seria anulada.

O amor, na ética da alteridade radicalizada, não necessita ser exposto, midiatizado, curtido, não é mais um dos instrumentos narcísicos da sociedade contemporânea exibicionista, visto que acontece na intimidade da morada do ser. Não é, portanto, um reservatório de desejos ocultos e reprimidos dos amantes que depositam no outro a responsabilidade por completá-los. É lugar de morada, onde 0 ser se constitui. $O$ amor, como sabiamente nos diz o personagem Riobaldo, em Grandes Sertões Veredas de Guimarães Rosa, é o 
descanso na loucura, é um pouquinho de saúde, é um abrigo no qual os amantes repousam e recomeçam suas jornadas de amar e ser amado.

O amor é um mandamento ético, de acordo com Lévinas, e subverte as atuais formas de amar contemporâneas. Ele nada tem de certo. Não se pode desvendar todos os seus mistérios. Como bem nos diz Bauman (2008b), numa leitura levinasiana, amar significa entrar numa relação com um mistério e concordar com sua falta de solução. O amor não significa agarrar, possuir ou conhecer aquele que mora no irrevelado. O amor é o consentimento para o mistério do outro, outro que nunca está lá, que quando chego já se foi, que não se mostra, mas que, em seu enigma, intima-me e convoca-me à responsabilidade por outrem. Esse outro que me ultrapassa e me constitui, sendo da mesma forma, o amor.

\section{REFERÊNCIAS}

Bauman, Z. (2004). O amor líquido. Sobre a fragilidade dos laços humanos. (C. A. Medeiros, Trad.) Rio de Janeiro, RJ: Zahar.

Bauman, Z. (2008a). Vida para consumo. A transformação das pessoas em mercadoria. (C. A. Medeiros, Trad.) Rio de Janeiro, RJ: Zahar.

Bauman, Z. (2008b). A sociedade individualizada: Vidas contadas e histórias vividas. (J. Gradel, Trad.) Rio de Janeiro, RJ: Zahar.

Braz, A. L. N. (2005). Origem e significado do amor na mitologia greco-romana. Estudos de Psicologia, 22(1), 63-75. doi:10.1590/S0103166X2005000100008

Carneiro, T. F. (1998). Casamento contemporâneo: o difícil convívio da individualidade com a conjugalidade. Psicologia Reflexão Crítica, 11(2), 379-394. doi:10.1590/S0102-79721998000200014

Coelho Júnior, N.E., \& Figueiredo, L. C. (2004). Figuras da intersubjetividade na constituição subjetiva: dimensões da alteridade. Interações, 9(17), 9-28.

Gadamer, H. G. (2008). Verdade e Método. Traços fundamentais de uma hermenêutica filosófica. (F.P. Meurer, Trad.) Petrópolis, RJ: Vozes.

Giddens, A. (1993). Transformações da intimidade. Sexualidade, amor e erotismo nas sociedades modernas. (P. Dentzien, Trad.) São Paulo, SP: UNESP.

Haddock-Lobo, R. (2006). Da existência ao infinito: Ensaios sobre Emmanuel Lévinas. São Paulo, SP: Loylola.

Lévinas, E. (1978). Autrement qu'être ou au delà de l'essence. Paris: Le Livre de Poche.

Lévinas, E. (1982). Ética e Infinito. (J. Gama, Trad.) Lisboa: Edições 70.

Lévinas, E. (1980). Totalidade e infinito. (J.P. Ribeiro, Trad.) Lisboa: Edições 70.

Lima, V. B. M. (2007). O conceito de amor em Emmanuel Lévinas (Dissertação de Mestrado). Pontifícia Universidade Católica de São Paulo, SP. 
Marcondes Filho, C. (2007). O outro como um mistério e o feminino como a alteridade absoluta. Sobre a recuperação do face-a-face na comunicação em Emmanuel Lévinas. Matrizes, (1), 55-74.

Penha, J. da. (1982). O que é existencialismo. São Paulo, SP. Editora Brasiliense.

Platão. (1972). Diálogos: O banquete. (J. Paleikate, Trad.) São Paulo, SP: Editor Victor Civita.

Poirié, F. (2007). Emmanuel Lévinas: ensaio e entrevistas. (M. Honório e Thiago, Trad.). São Paulo, SP: Perspectiva.

Pretto, Z., Maheirie, K., \& Toneli, M. J. F. (2009). Um olhar sobre o amor no ocidente. Psicologia em Estudo, 14(2), 395-403. doi:10.1590/S141373722009000200021

Rios, I. C. (2008). O amor em tempos de Narciso. Revista Interface, 15(25), 421-426. doi:10.1590/S1414-32832008000200016

Santos, T. S. (2011). Intersubjetividade em Sartre: O Para-si e o Para-outro. Trilhas Filosóficas, 4(2), 49-60.

Sartre, J. P. (1997). O ser e o nada. (P. Perdigão, Trad.) Petrópolis: Vozes.

Silva, P.C.G. (2010). O conceito de liberdade em o ser e o nada de Jean-Paul Sartre (Dissertação de Mestrado). Universidade Federal do Rio Grande do Norte, Rio Grande do Norte.

Zanello, V. (2007). O amor (e a mulher): Uma conversa (im)possível entre Clarice Lispector e Sartre. Estudos Feministas, 15(3), 531- 539. doi: 10.1590/S0104-026X2007000300002

Sobre os autores

Maria Juliana Viera Lima é graduada em Psicologia pela Universidade Federal do Ceará, especialista em Saúde da Criança e do Adolescente pelo programa de Residência Integrada em Saúde da Escola de Saúde Pública do Ceará, mestranda em Psicologia pela Universidade Federal do Ceará. mjulianavlima@hotmail.com José Célio Freire é graduado em Psicologia pela Universidade Federal do Ceará, mestre em Educação pela Universidade Federal do Ceará, doutor em Psicologia pela Universidade de São Paulo, com pós-doutorado na Universidad Complutense de Madrid. Professor Titular do Departamento de Psicologia e do Programa de Pós-graduação em Psicologia da Universidade Federal do Ceará. jcfreire@ufc.br

Recebido em: 28/06/2016

$1^{a}$ revisão em: 24/07/2016

$2^{a}$ revisão em: $31 / 10 / 2016$

Aceito em: 15/03/2017 